\title{
Overheidsmaatregelen om overgewicht tegen te gaan
}

\author{
'Effectief voor anderen, maar niet voor mij'
}

Charlotte M. Dieteren · Werner B. F. Brouwer · Igna Bonfrer

Geaccepteerd op: 13 juli 2021 / Published online: 4 augustus 2021

(C) The Author(s) 2021

\begin{abstract}
Samenvatting Het stimuleren van gezond gedrag staat hoog op de politieke agenda. Overheidsmaatregelen op het gebied van gezonde voeding staan echter nog in de kinderschoenen. Onlangs pleitte de Raad voor Volksgezondheid en Samenleving dan ook voor meer overheidsmaatregelen om ongezond eetgedrag tegen te gaan. Het ontwerpen van zulke maatregelen op een zowel acceptabele als effectieve wijze is complex. We legden zevenhonderd Nederlanders vijf stellingen voor met betrekking tot overheidsingrijpen op het gebied van gezonde voeding. We vroegen hen welk effect ze voor zichzelf en voor anderen verwachten van de maatregelen die zijn gesuggereerd in het zogenaamde Nationaal Preventieakkoord en eveneens zijn aangehaald door de Raad voor Volksgezondheid en Samenleving.
\end{abstract}

Trefwoorden leefstijl • overgewicht . overheidsmaatregelen $\cdot$ publieke opinie

\section{Policy interventions to reduce overweight 'Effective for others, but not for me'}

Abstract Promoting healthy behavior features high on the policy agenda. However, governmental interventions towards a healthy diet are still in their infancy. The Council for Public Health and Society recently

\footnotetext{
Digitaal aanvullende content De online versie van dit artikel (https://doi.org/10.1007/s12508-021-00314-x) bevat aanvullend materiaal, toegankelijk voor daartoe geautoriseerde gebruikers.

C. M. Dieteren $(\triangle)$ W W. B. F. Brouwer · I. Bonfrer Erasmus School of Health Policy \& Management (ESHPM), Erasmus Universiteit Rotterdam, Rotterdam, Nederland Erasmus Centre for Health Economics Rotterdam (EsCHER), Rotterdam, Nederland

Dieteren@eshpm.eur.nl
}

called for increased governmental action to prevent unhealthy diets. Designing both acceptable and effective measures is complex. We surveyed 700 Dutch adults and presented them with five statements regarding government intervention to stimulate healthy diets. We asked them what effect they expect for themselves and for others from the interventions suggested in the 'National Prevention Agreement' and by the Council for Public Health and Society.

Keywords Lifestyle $\cdot$ Overweight · Policy interventions · Public opinion

\section{Inleiding}

Eind 2018 is het eerste Nederlandse Nationaal Preventieakkoord gesloten [1]. Een brede coalitie van maatschappelijke partijen, het bedrijfsleven en de overheid heeft een pakket van maatregelen geformuleerd dat moet bijdragen aan een gezondere bevolking. Dit pakket is gebaseerd op drie pijlers van ongezond gedrag: roken, problematisch alcoholgebruik en overgewicht. Samen leiden deze drie vormen van ongezond gedrag tot een jaarlijkse ziektelast van ongeveer 35.000 doden als gevolg van te voorkomen oorzaken en kosten ze zo'n 9 miljard euro aan zorguitgaven [1]. Interventies gericht op gezonde voeding en het tegengaan van overgewicht staan nog in de kinderschoenen, terwijl inmiddels meer dan de helft van alle volwassen Nederlanders overgewicht heeft [2]. De urgentie van een verandering in de eetgewoonten van Nederlanders neemt daarmee toe. De Raad voor Volksgezondheid en Samenleving (RVS) pleit dan ook in haar recente rapport Een eerlijke kans op gezond leven voor structurele en wettelijke verplichtingen om gezondheidsachterstanden terug te dringen [3]. De maatregelen die eerder in het Preventieakkoord werden aangehaald zijn beduidend minder ingrijpend, waar- 
Figuur 1 Mogelijke overheidsmaatregelen rond gezond gewicht en percentage dat gelooft in de effectiviteit (1) of niet (0) voor respondent zelf versus anderen

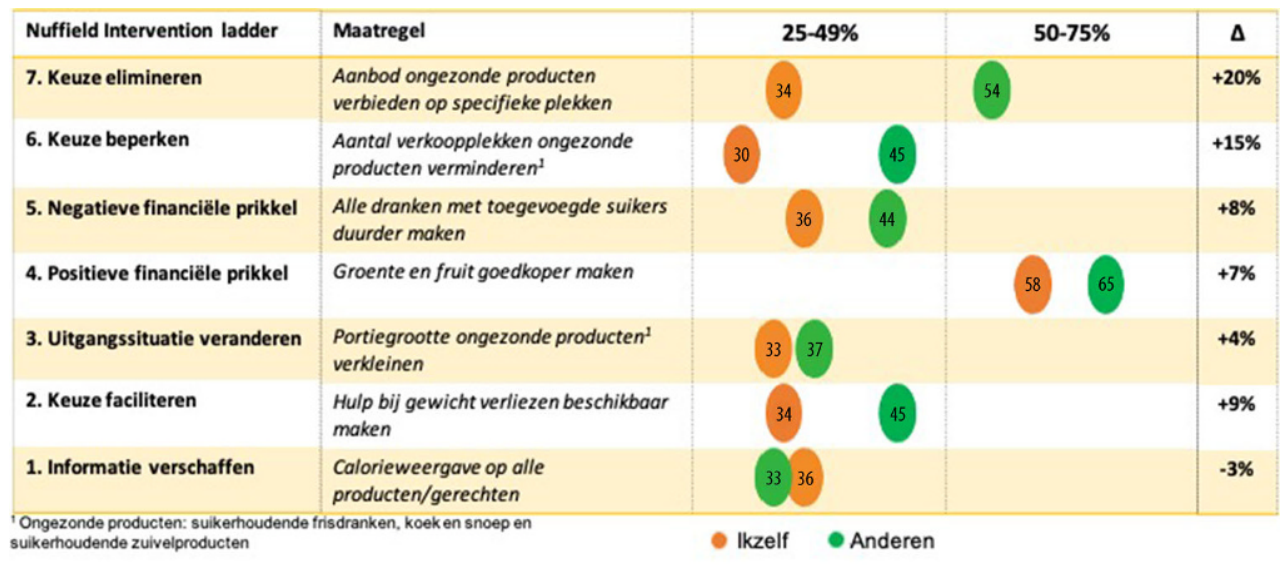

onder bijvoorbeeld een passend zorgaanbod om tot gedragsverandering te komen voor mensen met gewichtsproblematiek, het stimuleren van de verkoop van koek, chocola en snoep in kleinere porties, en het toepassen van nudging in supermarkten om klanten makkelijker gezonde producten te laten kopen.

De Britse Nuffield Intervention ladder rangschikt volksgezondheidsinterventies naar hun mate van overheidsingrijpen [4]. Zoals te zien is in fig. 1, bestaat de onderste trede uit de minst ingrijpende interventies en de zevende en daarmee bovenste trede uit de meest ingrijpende vormen van overheidsingrijpen. In Nederland is het overheidsingrijpen op het gebied van voeding vooralsnog beperkt en daarmee onder te brengen op de twee laagste treden van de Nuffield Intervention ladder. Ingrijpendere maatregelen, zoals invoering van een suikertaks of het verminderen van het aanbod van ongezonde voeding in sportkantines, worden al geruime tijd besproken, maar zijn nog niet algemeen bindend ingevoerd [5]. Mogelijk komt daar met het recente RVS-rapport verandering in, nu daarin wordt gepleit voor maatregelen hoger op de Nuffield Intervention ladder. Zo adviseert de RVS aan het Ministerie van Volksgezondheid, Welzijn en Sport dat gemeenten fastfoodwinkels moeten kunnen weren, er een suikertaks ingevoerd moet worden, en er een verlaging van de btw op gezond eten en een verbod op reclame voor ongezond voedsel moeten komen. Dergelijke ingrijpendere overheidsmaatregelen zijn niet onbekend in relatie tot andere vormen van ongezond gedrag. Zo is er op veel openbare plekken een rookverbod (trede 7) en is de verkoop van alcohol in tankstations verboden (trede 6).

Tussen de lagere en hogere treden op de Nuffield Intervention ladder is onder andere het toepassen van financiële prikkels gepositioneerd (treden 4 en 5 in fig. 1). Dergelijke maatregelen, zoals de suikertaks, worden algemeen beschouwd als een potentieel effectief stuurmiddel om gedrag te beïnvloeden [6]. Ze zouden dan ook een logische uitbreiding kunnen vormen op het Nederlandse beleid ter stimulering van een gezond eetpatroon. Nobelprijswinnaars Esther Duflo en Abhajit Banarjee toonden echter onlangs aan dat mensen financiële prikkels vaak effectiever achten in het veranderen van gedrag van anderen, dan in het veranderen van hun eigen gedrag [7]. Dit onderscheid suggereert dat mensen verwachten dat anderen hun gedrag meer veranderen door financiële prikkels dan zijzelf. Dit roept de vraag op of de effectiviteitsverwachtingen voor dit soort maatregelen een betrouwbare indicator vormen voor de uiteindelijke effectiviteit. Wanneer iedereen verwacht dat de interventie beter werkt bij anderen dan bij zichzelf, maar de eigen inschatting het meest accuraat is, zou dit bijvoorbeeld kunnen leiden tot een overschatting van het verwachte effect.

Albert Bandera is de grondlegger van de veelgebruikte 'self-efficacy theory' (zelfeffectiviteitstheorie) [8], die stelt dat geloof in eigen kunnen essentieel is voor succesvolle gedragsverandering. De self-efficacy kan verhoogd worden wanneer een vergelijkbaar succes wordt geobserveerd bij iemand anders. Meer algemeen is er naar ons weten niet eerder onderzocht of de zelfeffectiviteit en andereneffectiviteit van elkaar verschillen op het gebied van preventie of meer specifiek voedingsinterventies.

In dit onderzoek analyseren we of het onderscheid tussen verwachte effectiviteit voor jezelf ten opzichte van anderen optreedt in de Nederlandse context, en voor overheidsmaatregelen uit het preventieakkoord en het RVS-advies op het gebied van voeding. Omdat de voorgestelde interventies de grootste winst kunnen behalen bij mensen met overgewicht stratificeren we in dit onderzoek ook de resultaten naar respondenten zonder en met overgewicht (BMI $\geq 25$ op basis van zelfgerapporteerde lengte en gewicht).

\section{Aanpak}

In december 2020 is een online vragenlijst via e-mail uitgezet onder zevenhonderd volwassenen die onderdeel uitmaken van het online onderzoekspanel van Motivaction (ISO 20252:2019-gecertificeerd). Uit dit panel zijn zevenhonderd respondenten geselecteerd op basis van quota-sampling om een representatieve steekproef te krijgen van de Nederlandse bevolking in 
termen van leeftijd, geslacht en opleiding. De dataverzameling heeft een week geduurd. We hebben eerst in algemene zin acceptatie ten aanzien van overheidsingrijpen op het gebied van leefstijl gemeten door middel van vijf stellingen (supplement S.1). Vervolgens hebben we de respondenten zeven mogelijke overheidsmaatregelen op het gebied van gezonde voeding voorgelegd (fig. 1). Deze maatregelen zijn afkomstig uit het Nationaal Preventieakkoord (trede 1: 'calorieweergaven op producten/gerechten', trede 2: 'hulp bij gewicht verliezen beschikbaar maken', trede 3: 'portiegrootte ongezonde producten verkleinen') en sluiten aan bij door de RVS gesuggereerde maatregelen (trede 4: 'groente en fruit goedkoper maken', trede 5: 'alle dranken met toegevoegde suikers duurder maken', trede 6: 'aantal verkoopplekken ongezonde producten verminderen'), terwijl de laatste afkomstig is uit de literatuur (trede 7: 'aanbod ongezonde producten verbieden op specifieke plekken’). Voor alle zeven maatregelen is de verwachte effectiviteit bevraagd door middel van de volgende twee stellingen: 1) 'Door deze maatregel zou $i k z e l f$ minder ongezonde producten eten', 2) 'Door deze maatregel zullen anderen minder ongezonde producten gaan eten.' Subgroepanalyses zijn uitgevoerd op de stellingen en de verwachte effectiviteit op mensen met en zonder overgewicht om te bekijken of deze groepen significant van elkaar verschillen (met een chi-kwadraattoets) [9].

\section{Acceptatie van overheidsingrijpen op het gebied van gedrag}

In totaal hebben 698 respondenten de vragenlijst volledig ingevuld. Supplement S.2 beschrijft de kenmerken van deze onderzoekspopulatie. De gemiddelde leeftijd is vijftig jaar en iets meer dan de helft van de onderzoekspopulatie is vrouw (52\%). In totaal heeft $52 \%$ van de ondervraagden overgewicht (BMI $\geq 25$ ). Supplement S.3 beschrijft de bevindingen met betrekking tot de vijf voorgelegde stellingen. In de onderzoekspopulatie is $30 \%$ van mening dat de overheid zich niet moet bemoeien met de leefstijl van mensen, is $26 \%$ neutraal en is $44 \%$ het oneens met deze stelling ('De overheid moet zich niet bemoeien met de leefstijl van mensen'). Een ruime meerderheid (81\%) is voor overheidsingrijpen als het gedrag betreft dat derden schaadt en slechts $4 \%$ is hiertegen. Roken is bij uitstek een voorbeeld van gedrag dat derden schaadt, en het draagvlak voor overheidsingrijpen op dit terrein lijkt inderdaad groot. Op de vraag of de overheid verantwoordelijk mag worden gehouden voor de gezondheid van de bevolking, geeft ruim een kwart (28\%) aan het hiermee eens te zijn, terwijl $34 \%$ het hiermee oneens is en een iets grotere groep (38\%) neutraal is. Dit is ook relevant voor recente discussies over wettelijke verankering van gezondheidsdoelen [10]. Voorrang binnen de gezondheidszorg op basis van een gezonde leefstijl stuit op bezwaren in bijna de helft van de bevolking (46\%), terwijl $22 \%$ voorstander is. Ver- der vindt $56 \%$ van de respondenten dat de gevolgen van een ongezonde leefstijl voor eigen verantwoordelijkheid zijn en is slechts $17 \%$ het hiermee oneens. Deze cijfers laten zien dat er geen consensus bestaat over acceptatie van overheidsingrijpen, behalve voor gedrag dat derden schaadt en waarbij het draagvlak voor overheidsingrijpen groot is.

\section{Effectief voor anderen, maar niet voor $\mathrm{mij}$}

De rechterhelft van fig. 1 geeft voor alle maatregelen weer, geordend op de Nuffield Intervention ladder, hoeveel procent van de respondenten gelooft dat de maatregel daadwerkelijk een effect zal hebben op de consumptie van ongezonde producten. Dit is uitgesplitst naar het verwachte effect op henzelf en op anderen. De laatste kolom toont het verschil tussen zelfen anderen in procentpunten (pp).

Een algemene trend die uit fig. 1 naar voren lijkt te komen, is dat de verwachte effectiviteit groter is naarmate maatregelen hoger op de ladder staan. Die maatregelen kunnen tegelijkertijd overigens minder geaccepteerd worden. Een uitzondering en uitschieter hierbij blijkt de positieve prikkel in de vorm van subsidie (trede 4), waarvan een aanzienlijk groter effect wordt verwacht dan van de andere maatregelen, zowel voor zichzelf (58\%) als voor anderen (65\%).

De observatie dat men de effectiviteit bij anderen hoger inschat dan bij zichzelf lijkt voor elke trede van de Nuffield Intervention ladder op te gaan, behalve voor de laagste trede (informatie verschaffen).

Wanneer het effect dat men voor zichzelf verwacht als uitgangspunt wordt genomen, zou dit kunnen betekenen dat de verwachte effectiviteit van maatregelen op populatieniveau overschat wordt, wanneer deze (mede) wordt gebaseerd op verwachtingen over anderen.

In lijn met Duflo en Banarjee vinden wij dat mensen financiële prikkels voor anderen effectiever achten dan voor zichzelf (7 pp verschil). Dit geldt zowel voor de positieve prikkels (subsidie), als de negatieve (taks). Meer algemeen tekent zich een beeld af dat bij meer overheidsingrijpen (dat wil zeggen hogere treden), het verschil tussen het verwachte effect op zichzelf en anderen toeneemt. Op de hoogste trede, het verbieden van ongezonde producten, is het verschil $20 \mathrm{pp}$. Vergeleken met de zes andere soorten maatregelen verwachten de respondenten van een dergelijk verbod niet zozeer een groter effect op de eigen consumptie van ongezonde producten $(34 \%)$, als wel een relatief groot effect op anderen (54\%).

Stratificatie op basis van leeftijd liet een significant onderscheid zien in de te verwachte effectiviteit van financiële prikkels. Jongeren (18-35 jaar) verwachten een groter effect $(65 \%)$ op hun gedrag van een positieve financiële prikkel dan ouderen (51-70 jaar) (52\%). Verder verwachten juist de ouderen dat een negatieve financiële prikkel het meeste effect zal hebben op anderen (47\%). 


\section{En bij mensen met overgewicht?}

Men zou om meerdere redenen kunnen verwachten dat respondenten die zelf overgewicht hebben verschillen in hun acceptatie en inschatting van de effectiviteit van maatregelen van respondenten zonder overgewicht. Voor die laatste groep zou het effect op eetgedrag wellicht per definitie minder groot worden ingeschat. In onze onderzoekspopulatie heeft $53 \%$ overgewicht (een BMI van $\geq 25,0$ ), gebaseerd op zelfgerapporteerde lengte en gewicht, en heeft de andere $47 \%$ een BMI van onder de 25 , met een enkeling zelfs ondergewicht (een BMI lager dan 18,0, $n=13$ ) (zie supplement S.2).

Een onderscheid op basis van overgewicht laat zien dat een derde van de mensen zonder overgewicht (34\%) van mening is dat de overheid verantwoordelijkheid draagt voor de gezondheid van de bevolking, tegenover slechts $22 \%$ van de mensen met overgewicht $(p=0,002)$. Daarnaast vindt ruim een kwart $(27 \%)$ van de mensen zonder overgewicht dat mensen met een gezonde leefstijl voorrang moeten krijgen in de zorg, terwijl mensen met overgewicht hier aanzienlijk minder voorstander van zijn $(17 \%)(p=0,003)$. De overige stellingen laten geen significante verschillen zien.

In relatie tot de verwachte effectiviteit vinden we geen grote verschillen tussen de respondenten met en zonder overgewicht (supplement S.4). Alleen voor 'hulp bij gewicht verliezen beschikbaar maken' verwacht $39 \%$ van de respondenten met overgewicht effect van deze maatregel voor zichzelf en $44 \%$ voor anderen, vergeleken met respectievelijk 27 en $45 \%$ van de respondenten zonder overgewicht. Dit is mogelijk te verklaren doordat respondenten zonder overgewicht op korte termijn maar beperkt of geen baat hebben bij hulp bij gewichtsverlies voor zichzelf.

\section{Conclusie en beleidsaanbevelingen}

De door ons onderzochte overheidsmaatregelen om de Nederlandse bevolking te ondersteunen bij het bereiken of behouden van een gezond gewicht zijn onlangs door diverse partijen ter overweging voorgelegd aan beleidsmakers. Onze bevindingen suggereren dat mensen optimistischer zijn over de verwachte effectiviteit van deze maatregelen voor anderen dan voor zichzelf. Dit geldt vooral voor maatregelen waarbij de mate van overheidsingrijpen groot is, zoals het verbieden van ongezonde producten op specifieke plekken (bijvoorbeeld in sportkantines). Mogelijk leidt dit tot een overschatting van de te verwachte effectiviteit van maatregelen op de publieke gezondheid, vooral wanneer deze maatregelen ingrijpender zijn. De daadwerkelijke effectiviteit van de mogelijke overheidsmaatregelen rond gezond gewicht in de Nederlandse praktijk is echter nog grotendeels onbekend en vereist nader onderzoek. Volgens de self-efficacy-theorie van Bandera zou deze verhoogde verwachte effectiviteit voor anderen een gunstig effect kunnen hebben op de eigeneffectiviteit [8]. Wanneer andere mensen erin slagen om bijvoorbeeld vanwege een suikertaks minder ongezond voedsel te kopen, kan dit een positieve uitwerking hebben op andere mensen en kan dus de eigeneffectiviteit stijgen.

Het draagvlak voor overheidsingrijpen op het gebied van leefstijl lijkt op basis van onze bevindingen niet eenduidig. De verwachte effectiviteit van ingrijpendere maatregelen lijkt hoger, maar voor zulke maatregelen is acceptatie essentieel en niet vanzelfsprekend. Een uitzondering hierop is mogelijk de positieve financiële prikkel van het goedkoper maken van groente en fruit. Niet alleen verwachten onze respondenten daarvan de hoogste effectiviteit van alle voorgelegde maatregelen, maar is acceptatie van deze maatregel ook waarschijnlijker. We zien dat de verwachte effectiviteit hiervoor het hoogst is onder jongeren (18-35 jaar). Voor andere maatregelen die hoger op de ladder staan, waarvan sommige de RVS ook noemt, verwachten respondenten ook een relatief hoge effectiviteit. Het nader onderzoeken van het draagvlak onder de bevolking voor dergelijke maatregelen, en het onderzoeken van hun daadwerkelijke effectiviteit in de praktijk zou daarmee hoog op de onderzoekagenda moeten staan.

Open Access This article is licensed under a Creative Commons Attribution 4.0 International License, which permits use, sharing, adaptation, distribution and reproduction in any medium or format, as long as you give appropriate credit to the original author(s) and the source, provide a link to the Creative Commons licence, and indicate if changes were made. The images or other third party material in this article are included in the article's Creative Commons licence, unless indicated otherwise in a credit line to the material. If material is not included in the article's Creative Commons licence and your intended use is not permitted by statutory regulation or exceeds the permitted use, you will need to obtain permission directly from the copyright holder. To view a copy of this licence, visit http://creativecommons.org/licenses/by/4.0/.

\section{Literatuur}

1. Ministerie van VWS. Nationaal Preventieakkoord. 2018. http://www.nationaalpreventieakkoord.nl. Geraadpleegd op: 29 apr 2021.

2. CBS. Overgewicht: volwassenen. 2019. https://www. staatvenz.nl/kerncijfers/overgewicht. Geraadpleegd op: 29 apr 2021.

3. Raad Volksgezondheid en Samenleving. Een eerlijke kans op gezond leven. Den Haag: Raad Volksgezondheid en Samenleving; 2021.

4. Nuffield Council on Bioethics. Public health: ethical issues. 2007. https://www.nuffieldbioethics.org/assets/ pdfs/Public-health-ethical-issues.pdf. Geraadpleegd op: 29 apr 2021.

5. Kamphuis M, Hament J, Velpen P van. Geen suikertaks voor Nederland: een gemiste kans. Med Contact. 2018. https:// www.medischcontact.nl/nieuws/laatste-nieuws/artikel/ geen-suikertaks-voor-nederland-een-gemiste-kans.htm. Geraadpleegd op: 29 apr 2021. 


\section{Forum}

6. Giles EL, Robalino S, McColl E, Sniehotta FF, Adams J. The effectiveness of financial incentives for health behaviour change: systematic review and meta-analysis. Plos One. 2014;9(3):e90347.

7. Banerjee A, Duflo E. Economic incentives don't always do what we want them to. New YorkTimes. 2019;Sectie SR:4.

8. Bandura A. Self-efficacy: toward a unifying theory of behavioral change. Psychol Rev. 1977;84(2):191.

9. Plackett RL. Karl Pearson and the chi-squared test. Int Stat RevIntStat. 1983;51(1):59-72.

10. Skipr. Kamer wil wettelijke verankering gezondheidsdoelen. 2021. https://www.skipr.nl/nieuws/kamer-wilwettelijke-verankering-gezondheidsdoelen/. Geraadpleegd op: 29 apr 2021. 